\title{
Concerns about the widespread use of rodent models for human risk assessments of endocrine disruptors
}

\author{
René Habert ${ }^{1,2,3}$, Vincent Muczynski ${ }^{1,2,3}$, Tiphany Grisin ${ }^{1,2,3}$, Delphine Moison ${ }^{1,2,3}$, \\ Sébastien Messiaen ${ }^{1,2,3}$, René Frydman ${ }^{4}$, Alexandra Benachi ${ }^{4}$, Géraldine Delbes ${ }^{1,2,3,5}$, \\ Romain Lambrot ${ }^{1,2,3}$, Abdelali Lehraiki ${ }^{1,2,3}$, Thierry N'Tumba-Byn ${ }^{1,2,3}$, \\ Marie-Justine Guerquin ${ }^{1,2,3}$, Christine Levacher ${ }^{1,2,3}$, Virginie Rouiller-Fabre ${ }^{1,2,3}$ and \\ Gabriel Livera ${ }^{1,2,3}$
}

${ }^{1}$ Unit of Stem Cells and Radiation, Laboratory of Development of the Gonads, Sorbonne Paris Cité, Université Paris Diderot, BP 6, 92265 Fontenay-aux-Roses, France, ${ }^{2} C E A, D S V$, iRCM, SCSR, LDG, 92265 Fontenay-aux-Roses, France, ${ }^{3}$ Unité 967, INSERM, F-92265 Fontenay aux Roses, France, ${ }^{4}$ Service de Gynécologie-Obstétrique et Médecine de la Reproduction, Hôpital A. Béclère, Université Paris Sud, F-92141 Clamart, France and ${ }^{5}$ INRS- Institut Armand Frappier, Laval, Quebec, Canada H7V $1 B 7$

Correspondence should be addressed to R Habert at Unit of Stem Cells and Radiation, LDG/SCSR/iRCM/DSV, Centre CEA; Email: rene.habert@cea.fr

\begin{abstract}
Fetal testis is a major target of endocrine disruptors (EDs). During the last 20 years, we have developed an organotypic culture system that maintains the function of the different fetal testis cell types and have used this approach as a toxicological test to evaluate the effects of various compounds on gametogenesis and steroidogenesis in rat, mouse and human testes. We named this test rat, mouse and human fetal testis assay. With this approach, we compared the effects of six potential EDs ((mono-(2-ethylhexyl) phthalate (MEHP), cadmium, depleted uranium, diethylstilboestrol (DES), bisphenol A (BPA) and metformin) and one signalling molecule (retinoic acid (RA)) on the function of rat, mouse and human fetal testis at a comparable developmental stage. We found that the response is similar in humans and rodents for only one third of our analyses. For instance, RA and MEHP have similar negative effects on gametogenesis in the three species. For another third of our analyses, the threshold efficient concentrations that disturb gametogenesis and/or steroidogenesis differ as a function of the species. For instance, BPA and metformin have similar negative effects on steroidogenesis in human and rodents, but at different threshold doses. For the last third of our analyses, the qualitative response is species specific. For instance, MEHP and DES affect steroidogenesis in rodents, but not in human fetal testis. These species differences raise concerns about the extrapolation of data obtained in rodents to human health risk assessment and highlight the need of rigorous comparisons of the effects in human and rodent models, when assessing ED risk.
\end{abstract}

Reproduction (2014) 147 R119-R129

This paper forms part of a special issue of Reproduction on Endocrine Disrupters. This article was presented at the 7th Copenhagen Workshop on Endocrine Disrupters, 28-31 May 2013. The meeting was supported by the Danish Ministry of the Environment - Environmental Protection Agency as an activity under the Danish Centre on Endocrine Disrupters. Publication of this special issue has been supported by the Society for Reproduction and Fertility. The opinions or views expressed in this special issue are those of the authors, and do not necessarily reflect the opinions or recommendations of the Danish Ministry of the Environment - Environmental Protection Agency or the Society for Reproduction and Fertility. The Guest Editors for this special issue were Anna-Maria Andersson, Hanne Frederiksen, Niels Erik Skakkebæk, Rigshospitalet, Denmark, Kenneth M Grigor, Western General Hospital, Edinburgh, UK and Jorma Toppari, University of Turku, Finland.

\section{Introduction}

In regulatory toxicology, the human health risk from exposure to a given endocrine disruptor (ED) is classically assessed using animal, especially rodent, models followed by an extrapolation of the data to humans. Generally, to define the regulatory acceptance for human health, the lowest no observed adverse effect level (NOAEL) measured in the rodent model is divided by a safety factor equal to ten to account for the difference between rodents and humans and by an additional tenfold uncertainty factor to account for interindividual differences in susceptibility.

However, differently from fundamental processes such as cell differentiation, mitosis and carcinogenesis, 
many endocrine processes largely vary from one species to another. These species differences are even more pronounced for reproductive functions. Thus, the relevance of extrapolating animal data to human risk assessment should be questioned when assessing ED effects on reproductive functions.

The incidence of abnormalities of the male reproductive function has been increasing over the years (reviewed in Sharpe \& Irvine (2004), Leridon \& Slama (2008), and Main et al. (2010)). Human sperm count has been markedly decreasing and the rate of testicular cancer has clearly increased over the past four decades. Moreover, the prevalence rates of cryptorchidism and hypospadias are also probably increasing. More epidemiological, clinical and experimental data suggest that these male reproductive disorders could be due at least in part to the effects of EDs, which are becoming ever more concentrated and prevalent in our environment (Sharpe \& Skakkebaek 1993, reviewed in Delbès et al. (2006) and Vandenberg et al. (2012)). Furthermore, it has been hypothesized that these alterations are symptoms of a single syndrome named 'testicular dysgenesis syndrome' (TDS), resulting from abnormalities in testis development during fetal life (Skakkebaek et al. 2001, Olesen et al. 2007). Thus, the fetal testis is a very relevant target to study the species differences in ED effects.

Fetal testis performs two major functions: gametogenesis and steroidogenesis (reviewed in Olaso \& Habert (2000), Habert et al. (2001), and O'Shaughnessy \& Fowler (2011)). Sertoli cells, which surround germ cells to form the seminiferous cords, are the first to differentiate at 11.5 days post-conception (dpc) in mice, $13.5 \mathrm{dpc}$ in rats and $42-45 \mathrm{dpc}$ in humans. Sertoli cells divide actively until puberty and then remain quiescent. In adult life, sperm production will depend on the number of Sertoli cells formed during this period (reviewed in Sharpe (2012)). In the early fetal testis, germ cells originated from migrating primordial germ cells, which are named gonocytes, proliferate. In rodents, they enter synchronously a quiescent period during which mitosis and apoptosis are arrested so that the number of gonocytes does not change (from 18.5 dpc to 3-4 days post-partum (dpp) in rats and from $15.5 \mathrm{dpc}$ to $0-1 \mathrm{dpp}$ in mice). In humans, from the beginning of the second trimester, gonocytes progressively differentiate into prespermatogonia (also called prospermatogonia or fetal spermatogonia) that no longer express C-KIT and OCT4 (Franke et al. 2004, Gaskell et al. 2004), similar to rodent germ cells during late neonatal life. These cells enter nonsimultaneously a quiescent period for one group (Gaskell et al. 2004) whereas, for another group, some of these cells go on cell cycle (Pauls et al. 2006). Importantly, the differentiation of germ cells is not synchronous so that, even if each germ cell entered a quiescent period, the total number of germ cells per testis continuously increases during the whole fetal life in humans. As gonocytes give rise to the adult spermatogonial stem cells during neonatal life, correct development of the germ cell lineage during fetal/embryonic life is essential for the production of spermatozoa during adult life. Fetal Leydig cells differentiate soon after Sertoli cells and produce testosterone and insulin-like factor 3 (INSL3) that are required for the embryo phenotypic masculinization (reviewed in Scott et al. (2009) and Bay et al. (2011)).

In the 1990s, we developed an organotypic culture system, which we named fetal testis assay (FeTA; Habert et al. 1991, Lecerf et al. 1993, Olaso et al. 1998, Livera et al. 2000), that allows maintaining both gametogenesis and steroidogenesis of the rat fetal testis explants for a few days. We have adapted the system to mouse and human fetal testes over the past 10 years and this system allows a rigorous inter-species comparison of the fetal testis responsiveness and susceptibility to various chemicals. We review here data obtained for several EDs, the anti-diabetic drug metformin and retinoic acid (RA), a major paracrine/autocrine factor in fetal testis, covering a broad spectrum of genes and pathways potentially targeted by the chemicals and involved in toxicant-induced phenotypes.

\section{An experimental model to compare human, mouse and rat fetal testis responsiveness}

\section{Choice of the system}

One simple ethically acceptable way to evaluate directly the effect of a chemical compound in the human species is the use of in vitro approaches. However, the main limitation of toxicological studies using in vitro systems is the inability to reproduce the in vivo cell activities and fates. For instance, in cell culture systems, fetal Leydig cells dedifferentiate in the absence of specific gonadotropic stimulation (Habert \& Brignaschi 1991, Rouiller-Fabre et al. 1998) and isolated gonocytes do not survive well (Boulogne et al. 2003). Organ culture systems in which the testis architecture and intercellular communications are preserved appeared to us to be a relevant method to maintain the development of fetal or neonatal testis. In the 1990s, we compared different in vitro systems and found that the best functional and histological results were obtained by placing rat fetal testis explants on a membrane that floats on the culture medium at the air-medium interface (Habert et al. 1991). This organotypic culture system allows reproducing in vitro the normal development of testis somatic and germ cells without addition of any exogenous signalling factor (Habert et al. 1991, Lecerf et al. 1993, Olaso et al. 1998, Livera et al. 2000). We then adapted this methodology also to the culture of mouse and human fetal testes (Lambrot et al. 2006a, Livera et al. 2006). We then validated this organotypic culture system under the name of rat, mouse and human FeTA $(\mathrm{r} / \mathrm{m} / \mathrm{h}$ FeTA) as a tool to study the age-, time- and dose-dependent direct effects of various compounds on fetal testis functions and 


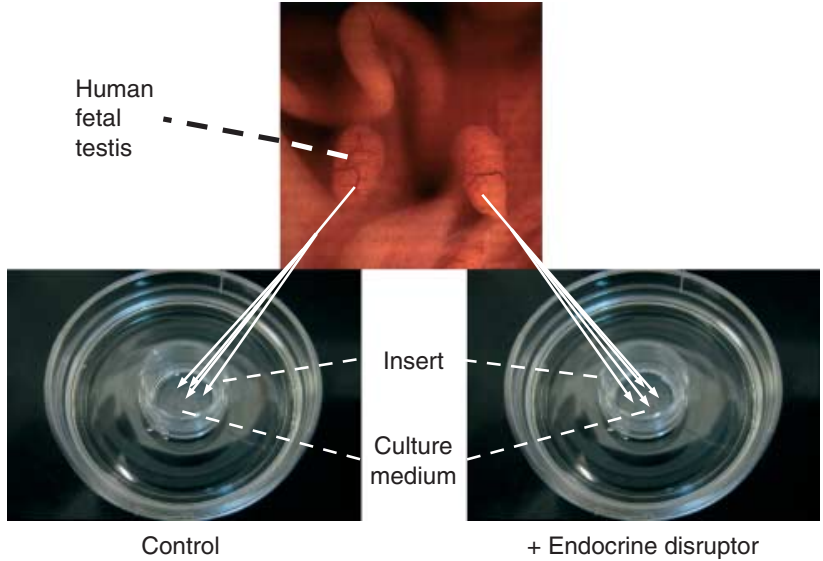

Figure 1 The fetal testis assay (FeTA). Human (6-12 GW), rat (14.5 dpc) or mouse (12.5 dpc) fetal testes are cultured on Millicell-CM Biopore membranes (pore size $0.4 \mu \mathrm{m}$, Millipore, Billerica, MA, USA) floating on $320 \mu \mathrm{l}$ culture medium in tissue culture dishes at $37^{\circ} \mathrm{C}$ in a humidified atmosphere containing 95\% air/5\% $\mathrm{CO}_{2}$. The culture medium is phenol red-free DMEM/Ham F12 (1:1) without biological factors and hormones. The culture medium is completely changed every $24 \mathrm{~h}$. Whole mouse and rat testes are cultured on the membrane, while human testes are cut into small pieces (around $0.2 \mathrm{~mm}^{3}$ ) due to their larger size and three to four pieces are randomly placed on the membrane (two to eight wells per testis). The secretion of various molecules in the medium (testosterone, INSL3, AMH, transferrin, lactate, etc.) can be quantified every day. At the end of the culture, explants can be fixed and tissue sections can be used to assess, for instance, the total number of cells per testis, apoptotic activity (cleaved caspase 3, TUNEL assay) or mitotic activity (Ki67, BrdU incorporation), expression of Leydig cell (steroidogenic actors, INSL3, LH Receptors, etc.), Sertoli cell (AMH, SOX9, etc.) and germ cell markers (pluripotency genes, such as OCT3-4, NANOG and differentiation genes such as c-KIT, NANOS2 and DNMT3L).

development (Lambrot et al. 2006b). This organotypic culture system has also been used by others for rat (Cupp \& Skinner 2001, Li \& Kim 2003, Stroheker et al. 2006, Chauvigné et al. 2009) and human testis explants (Bendsen et al. 2001, Robinson et al. 2003, Hallmark et al. 2007). Recently, we also showed that the $\mathrm{r} / \mathrm{m} / \mathrm{h}$ FeTA assay is a valuable toxicological assay by demonstrating that the in vivo effects of mono-2ethylhexyl phthalate (MEHP) during mouse fetal testis development could be reproduced in our culture system (Muczynski et al. 2012). The hFeTA assay and the histological features of human fetal testis explants at the end of the culture period are presented in Figs 1 and 2 .

\section{When to do the explants?}

Using this culture system, we observed clear age-related changes in the fetal testis responsiveness to various compounds. For instance, gonadotropin-releasing hormone $(\mathrm{GNRH})$, a putative paracrine testicular factor, does not have any effect on testosterone secretion in 14.5 dpc rat fetal testes, whereas it has negative effects in
16.5-18.5 dpc testes and positive effects in testis explants from 20.5 dpc onwards (Habert et al. 1991). Oestradiol and diethylstilboestrol (DES) reduce testosterone production in $14.5 \mathrm{dpc}$ rat fetal testis explants, but not in older specimens (Delbès et al. 2007). Similarly, the development of the germ cell lineage is affected differently as a function of age. MEHP apoptotic effect on gonocytes is much stronger in 11.5-13.5 dpc mouse fetal testis explants than in neonatal ones (Lehraiki et al. 2009). Age-related changes in the gonocyte response to various factors (RA, triiodothyronine, phorbol ester) have also been observed in cultures of dispersed testicular cells (Boulogne et al. 2003). Thus, to compare different species, it is necessary to choose a similar stage of development. We obtained human fetal testis samples from abortions carried out between the 6th and the 12th gestational week (GW), which corresponds to a period when testosterone secretion is increasing and gonocytes are proliferating (Rouiller-Fabre et al. 2009). To compare age-matched fetal testes from the three species, we decided to use $14.5 \mathrm{dpc}$ rat (Habert \& Picon 1984, Boulogne et al. 1999) and $12.5 \mathrm{dpc}$ mouse testes (Vergouwen et al. 1991, Livera et al. 2006).

\section{Choice of culture conditions}

Steroidogenesis can be measured using two parameters: i) the basal secretion of testosterone (i.e. in the absence of placental leutenizing hormone (LH) or human chorionic gonadotropin, hCG) that, in short-term cultures, reflects the in vivo testis activity (Habert \& Picon 1982) and ii) the secretion of testosterone in the presence of $\mathrm{LH} / \mathrm{hCG}$ to measure the explant maximum steroidogenic capacity. In utero decapitation of 16.5-18.5 dpc rat fetuses, a surgical operation that suppresses LH in fetal plasma and that is compatible with embryo survival, reduces basal but not $\mathrm{LH}$-stimulated testosterone secretion in vitro, showing that endogenous $\mathrm{LH}$ is necessary for basal in vivo steroidogenic activity but not for the differentiation of Leydig cells (Migrenne et al. 2001). Moreover, in 18.5 dpc rat testis explants, addition of a GNRH agonist increases the basal secretion and decreases the LH-stimulated secretion of testosterone (Habert et al. 1991). Thus, when comparing the effect of a compound in different species, it is important to use the same parameters (basal or LH-stimulated testosterone secretion).

\section{Strengths and limits of the FeTA}

The advantages of the organotypic culture system to study the chemical effects are numerous. This method allows the investigation of direct effects of chemicals alone or in mixture upon the fetal testis development and function. It allows a precise study of their kinetics of action and the duration and level of exposure is precisely controlled. These cultures are carried out in a defined 

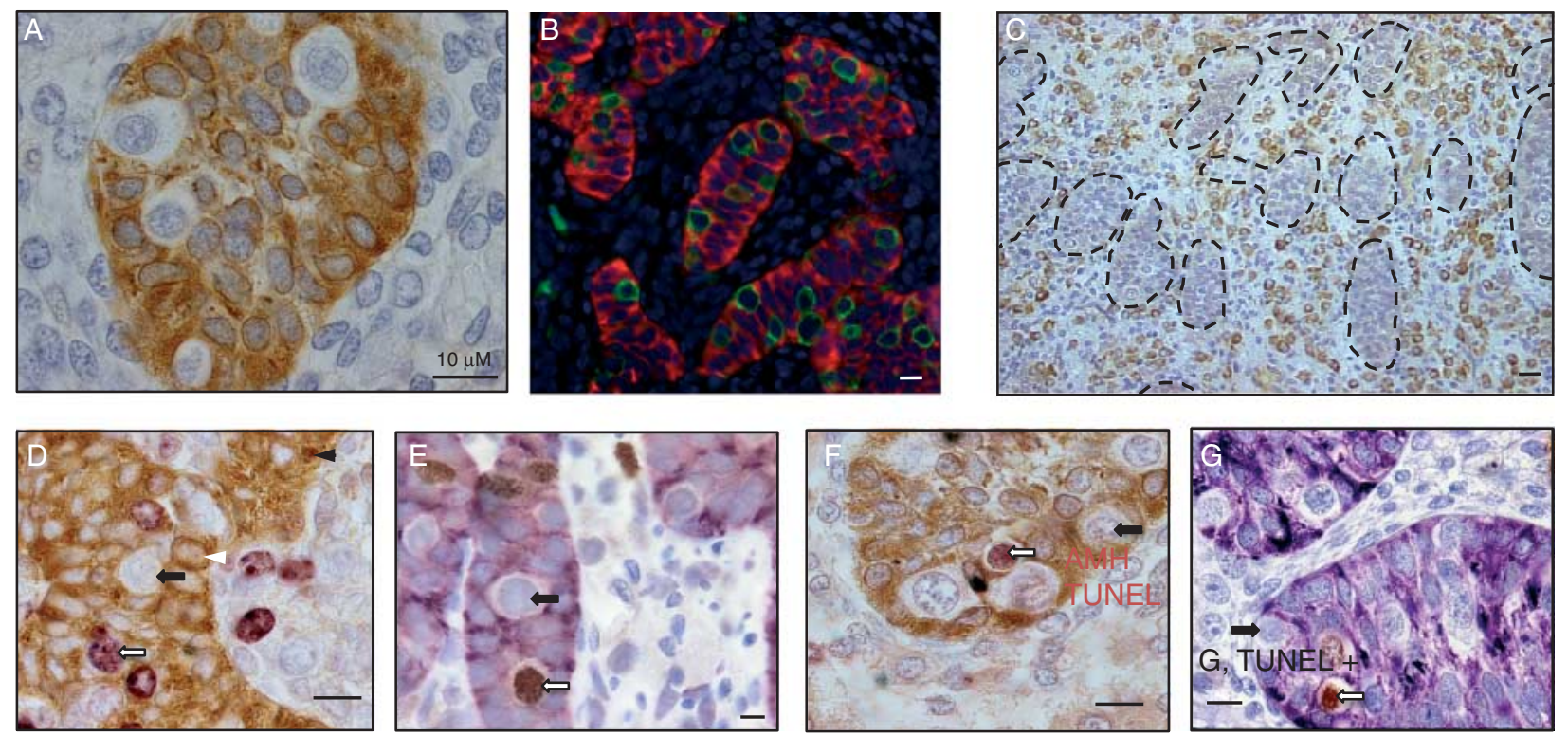

Figure 2 Immunohistological features of human fetal testis explants after culture. (A) AMH expression. In tissue sections from a ten GW human testis explant, Sertoli cells were immunostained with anti-AMH antibodies (brown cytoplasm). Gonocytes are identified as white cells inside the seminiferous cords. Bar: $10 \mu \mathrm{M}$. (B) Double immunofluorescence for AMH and M2A (9.5 GW human testis explants). M2A staining (green) is exclusively localized in gonocytes, characterized as large seminiferous cells that do not express AMH, a marker of Sertoli cells (red). Scale bar: $10 \mu \mathrm{M}$. (C) Cytochrome P450 scc expression. (9 GW human testis explant). Leydig cells are identified by cytochrome P450 scc expression. They are localized in the interstitial tissue between the seminiferous cords, which are here delineated by a dotted line. Scale bar: $20 \mu \mathrm{M}$. (D) Double immunostaining for AMH and Ki67 (7.5 GW human testis explant). Sertoli cells are identified by AMH expression (brown) and cycling cells are Ki67positive (purple). Black arrow: Ki67-negative gonocyte. White arrow: Ki67-positive gonocyte. White arrowhead: Ki67-negative Sertoli cell. Black arrowhead: Ki67-positive Sertoli cell. Scale bar: $10 \mu \mathrm{M}$. (E) Double immunostaining for AMH and BrdU (10.7 GW human testis explant). BrdU was added $2 \mathrm{~h}$ before the end of the culture. Sertoli cells are identified by AMH expression (purple) and cycling cells in S phase are detected by immunostaining for BrdU (brown). Black arrow: BrdU-negative gonocyte. White arrow: BrdU-positive gonocyte. Scale bar: $10 \mu \mathrm{M}$. (F) Double immunostaining for AMH and TUNEL (11.5 GW human testis explant). Sertoli cells are identified by AMH expression (brown cytoplasm) and gonocytes as cells with white cytoplasm inside the seminiferous cords. Apoptotic cell are identified by TUNEL assay (brown nucleus). Black arrow: TUNEL-negative gonocyte. White arrow: TUNEL-positive gonocyte. Scale bar: $10 \mu \mathrm{M}$. (G) Double immunostaining for AMH and cleaved caspase 3 (ten GW human testis explant). Sertoli cells are identified by AMH expression (purple cytoplasm) and gonocytes as cells with white cytoplasm inside the seminiferous cords. Apoptotic cell are identified by immunostaining for cleaved caspase 3 (brown nucleus). Black arrow: caspase 3-negative gonocyte. White arrow: caspase 3-positive gonocyte. Scale bar: $10 \mu \mathrm{M}$.

medium (usually with no phenol red), thus avoiding cross-contamination with other biologically active molecules. The treated testicular explants are compared with explants issued from the same testis (when the fetal testes are large enough to be cut into different pieces, i.e. with human or older rodent testes) or with the contralateral testis from the same fetus (for 14.5-15.5 $\mathrm{dpc}$ rat and 12.5-13.5 dpc mouse fetuses) that are cultured with vehicle only and served as controls. This paired analysis limits individual variability and increases the sensitivity of the method. As pregnant rodent females can produce up to 15 embryos, it is possible to assay various doses or different compounds with a single pregnant female, thus reducing the number of animals killed in comparison with in vivo approach. FeTA is also largely less time- and labour-intensive and cheaper than in vivo approaches. FeTA is a convenient model to investigate the mechanism of action of ED. The use of fetal testes from transgenic mice easily allows the identification of the pathway involved in chemical effects. As an example, unlike the DES effect, the negative effect of bisphenol A (BPA) on testosterone produced by the WT mouse fetal testis was maintained when using an $E R \propto K O$ fetal testis. This suggests a specific signalling pathway for BPA, which does not involve ER $\alpha$ and differs from the DES mode of action (Delbès et al. 2005, N'Tumba-Byn et al. 2012). Interestingly, such an experimental approach allows the use of transgenic mice in which knocking out the gene is lethal during gestation. Indeed, this method allows the maintenance of the development of the testis even beyond the death of the fetus (Petre-Lazar et al. 2007). Lastly, as shown in this paper, FeTA brings a valuable help in the translation of animal data to human beings.

As with each model, FeTA also has inherent limits. The main one is that long-term effects cannot be studied using this system as the development of the testis is maintained in vitro only for a few days $(\sim 4-10$ days depending on the species, the stage at sampling and the studied endpoint). Especially, this drawback is significant 
for the overall study of fetal gametogenesis in the human species that is a slow process. Xenograft of human fetal testes into immunodeficient rodent allows such longterm studies (Mitchell et al. 2010). However, for human fetal testicular steroidogenesis, there is no advantage in using the xenograft model in comparison with organotypic culture as the former is highly more time-, moneyand animal-intensive and displays a higher variability than the latter. Furthermore, the metabolism of the chemicals in the rodent host can differ from that in humans. FeTA is a system that does not permit the study of delayed effect such as abnormal spermatogenesis. Such long-term effects that may result from alterations of the differentiation of the gonocytes that are the precursors of spermatogonia stem cells must be studied in vivo. Another drawback of the in vitro approach is that this method only allows study of the direct effect without considering the potential extra testicular feedback loops that could compensate the effects of exogenous chemicals. Moreover, it does not take into account the indirect effect that these molecules can exert, for instance via a change in the activities of the placenta or of the hypothalamo-hypophysis axis that are known to play a role in testis development.

\section{Species-dependent effects of various chemical compounds on fetal testis function}

Using the $r / m / h$ FeTA system, we compared the effects of seven compounds on gametogenesis and steroidogenesis in rat, mouse and human fetal testes explants. Results are summarized in Fig. 3.

\section{Phthalates}

In vivo models have shown that phthalates impair gonocyte development in the rat (Barlow et al. 2003, Ferrara et al. 2006, reviewed in Habert et al. (2009)). Increased gonocyte apoptosis was also observed in vitro using the FeTA system in rat, mouse and human fetal testis explants (Chauvigné et al. 2009, Lambrot et al. 2009, Lehraiki et al. 2009). Conversely, MEHP induced the appearance of multinucleated gonocytes only in mouse and rat but not in human fetal testis explants. Moreover, MEHP did not affect testosterone production in human fetal testis explants (Lambrot et al. 2009). This was surprising because phthalates are considered anti-androgenic compounds based on their inhibitory action on in vivo production of testosterone in the rat

\begin{tabular}{|c|c|c|c|c|c|c|c|c|}
\hline \multirow{3}{*}{ Chemical } & \multirow{3}{*}{$\begin{array}{l}\text { Concentration } \\
\text { (M) }\end{array}$} & \multicolumn{3}{|c|}{ Effect on germ cell development } & \multicolumn{3}{|c|}{ Effect on Leydig cell function } & \multirow{3}{*}{ References } \\
\hline & & \multicolumn{3}{|c|}{ Species } & \multicolumn{3}{|c|}{ Species } & \\
\hline & & Human & Rat & Mouse & Human & Rat & Mouse & \\
\hline \multirow{3}{*}{ MEHP } & $10^{-6}$ & No & No & No & No & No & No & \multirow{3}{*}{$\begin{array}{l}\text { Lambrot et al. (2009), Lehraiki et al. (2009), } \\
\text { Muczynski et al. (2012), Data in this paper. }\end{array}$} \\
\hline & $10^{-5}$ & Negative & Negative & Negative & No & Negative & Positive & \\
\hline & $10^{-4}$ & Negative & Negative & Negative & No & Negative & Positive & \\
\hline \multirow{5}{*}{ BPA } & $10^{-12}$ & - & - & - & No & No & No & \multirow{5}{*}{ N'Tumba-Byn et al. (2012) } \\
\hline & $10^{-8}$ & - & - & - & Negative & No & No & \\
\hline & $10^{-7}$ & - & - & - & Negative & No & No & \\
\hline & $10^{-6}$ & - & - & - & Negative & - & No & \\
\hline & $10^{-5}$ & - & - & - & Negative & Negative & Negative effect & \\
\hline \multirow{2}{*}{ DES } & $10^{-6}$ & No & Negative & Negative & No & Negative & Negative & \multirow{2}{*}{$\begin{array}{c}\text { Delbès et al. (2006), N'Tumba Byn et al. (2012), } \\
\text { Habert R, Lambrot R, Grisin T, Moison D, } \\
\text { Livera G \& Rouiller-Fabre V (personal data) }\end{array}$} \\
\hline & $10^{-5}$ & No & Negative & Negative & No & Negative & Negative & \\
\hline \multirow{4}{*}{ Uranium } & $10^{-5}$ & No & - & No & - & - & - & \multirow{4}{*}{ Angenard et al. (2011) } \\
\hline & $5.10^{-5}$ & Negative & - & No & - & - & - & \\
\hline & $10^{-4}$ & Negative & - & Slightly negative & No & - & No & \\
\hline & $5.10^{-4}$ & Negative & - & Negative & - & - & - & \\
\hline \multirow{3}{*}{ Cadmium } & $10^{-7}$ & No & - & - & No & - & No & \multirow{3}{*}{ Angenard et al. (2010) } \\
\hline & $10^{-6}$ & Negative & - & No & No & - & No & \\
\hline & $10^{-5}$ & Negative & - & Negative & No & - & No & \\
\hline \multirow{4}{*}{ Metformin } & $5.10^{-5}$ & - & - & - & Negative & - & No & \multirow{4}{*}{ Tartarin et al. (2012) } \\
\hline & $5.10^{-4}$ & - & - & - & Negative & - & Slightly negative & \\
\hline & $10^{-3}$ & - & - & - & Negative & - & Negative & \\
\hline & $5.10^{-3}$ & - & - & - & Negative & - & Negative & \\
\hline \multirow[b]{2}{*}{ Retinoic acid } & $3.10^{-8}$ & - & Negative & - & - & No & - & \multirow{2}{*}{$\begin{array}{l}\text { Livera et al. (2000), Lambrot et al. (2006a,b), } \\
\text { Trautman et al. (2008), Livera G, Grisin T, } \\
\text { Guerquin MJ \& Habert R (personal data) }\end{array}$} \\
\hline & $10^{-6}$ & Negative & Negative & Negative & $\begin{array}{l}\text { Positive (<7GW) } \\
\text { or no (>7GW) }\end{array}$ & Negative & Positive & \\
\hline
\end{tabular}

Figure 3 Comparison of the effects of seven chemicals on gametogenesis and steroidogenesis in human, rat and mouse fetal testis. Testes from 6 to 12 GW (human), $14.5 \mathrm{dpc}$ (rat) or $12.5 \mathrm{dpc}$ (mouse) fetuses were cultured for 3 or 4 days as described in the legend of Fig. 1 . The culture medium, which did not contain any biological factor or hormone, was completely changed every $24 \mathrm{~h}$. Germ cell development was assessed at the end of the culture period by quantifying the total number of gonocytes per testis, the apoptotic rate (percentage of TUNEL-positive or caspase 3-positive gonocytes) and the mitotic rate (percentage of gonocytes that incorporate BrdU added in the medium for the last $2 \mathrm{~h}$ of culture). Leydig cell function was assessed by quantifying the daily secretion of testosterone. No: not detectable effect; negative: the chemical reduces the number of gonocytes (and/or increases the apoptosis and/or decreases the mitotic rate) or decreases testosterone production; positive: the chemical increases the number of gonocytes (and/or decreases the apoptosis and/or increases the mitotic rate) or increases testosterone production; -: not performed. White area: the response is similar in human and rodent testes. Grey area: the response is qualitatively similar in human and rodent testes, but the NOAEL is different. Black area: the response qualitatively differs between human and rodent testes. 
(reviewed in Habert et al. (2009) and Scott et al. (2009)). One explanation could be that in vitro systems are unsuitable for detecting the anti-androgenic effects of phthalates. Indeed, some authors found that addition of MBP or MEHP to cultured rat fetal testes do not affect testosterone production (Stroheker et al. 2006, Hallmark et al. 2007). Conversely, MEHP increased or did not change the basal or LH-stimulated testosterone production by mouse fetal testis explants in the FeTA system (Lehraiki et al. 2009). However, another study reported a MEHP-induced reduction of testosterone secretion by fetal rat testes cultured in the FeTA system (Chauvigné et al. 2009). This effect could be observed when only half of the medium was changed daily, but not when the medium was completely changed every $24 \mathrm{~h}$ (i.e. the conditions we used for human testes in the study by Lambrot et al. 2009). This made us question our conclusion that phthalates are not anti-androgenic in the human species. Thus, we recently re-evaluated the effect of phthalates on testosterone production in rat fetal testes cultured rigorously following the same conditions as those we had used previously for human fetal testis (i.e. daily change of the whole medium). Original data are presented in Fig. 4B. We found that, unlike the results of Chauvigné et al. (2009), MEHP induced a dose- and time-dependent decrease in testosterone production in cultured rat fetal testis explants (Fig. 4). Thus, the rat model can be used as a positive control to validate the absence of phthalate effects on the steroidogenic response in human testis explants. Furthermore, we confirmed that MEHP increases germ cell apoptosis as the percentage of caspase 3-positive cells increased from $0.86 \pm 0.25$ in controls to $8.14 \pm 0.13$ in $10^{-4} \mathrm{M} \mathrm{MEHP-}$ treated testes at day 3 (D3) of culture. We cannot explain why Chauvigné et al. (2009) could not observe a steroidogenic effect of MEHP with a complete daily change of the medium. Nevertheless, this emphasizes that inter-species comparisons need to be carried out following a rigorous approach: i) selecting ages of gestation where the same events are occurring, ii) using an identical method across the different species that supports gametogenesis and steroidogenesis, iii) using explants with very similar size, iv) using explants that are not contaminated with mesonephros and v) reducing experimentation variability by using the same investigators and the same material.

The recent observations that di-n-butyl phthalate decreases steroidogenic activity in rat fetal testes but not in human fetal testes grafted into a host mouse or rat (Heger et al. 2012, Mitchell et al. 2012) definitively confirms that phthalates are not anti-androgenic compounds for human fetal testis.

\section{Bisphenol A}

The FeTA system showed that the minimum BPA concentration required to impair testosterone
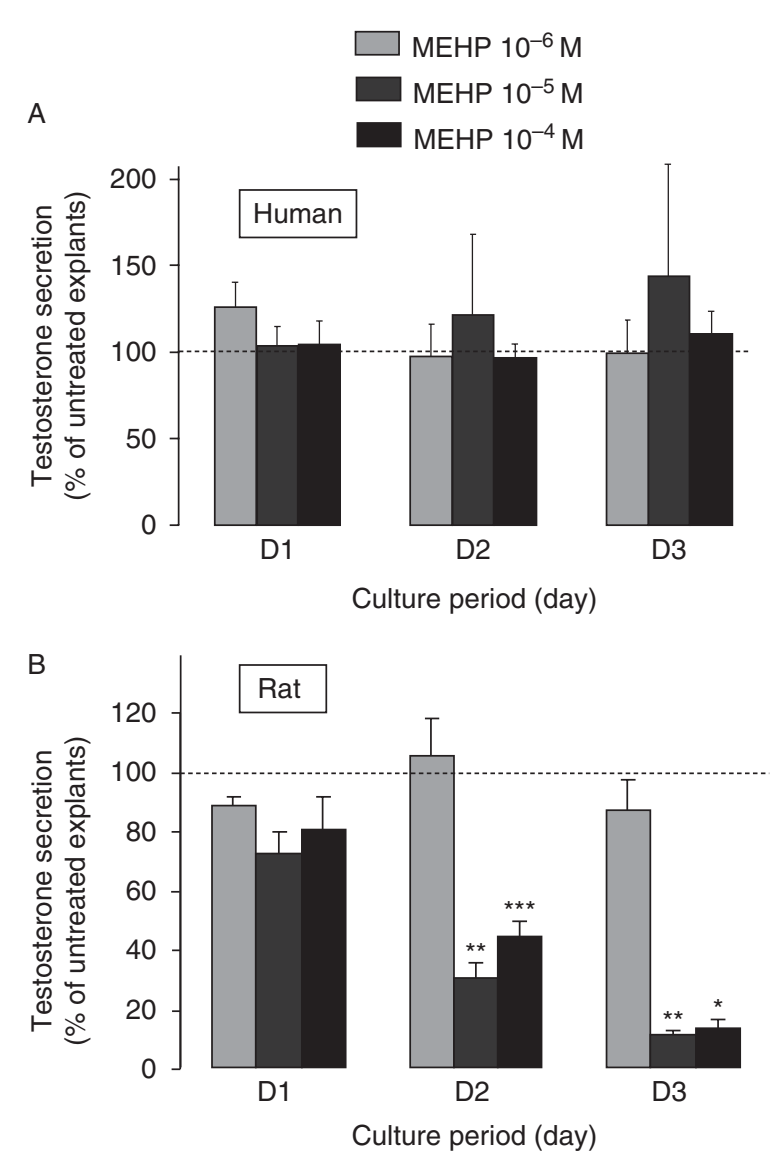

Figure 4 Effect of MEHP on testosterone secretion by cultured rat and human fetal testis explants. Testes from 7 to $11 \mathrm{GW}$ human fetuses (A) to 14.5-day-old rat fetuses (B) were cultured using the FeTA system, a method in which the explants are deposited on floating membrane at the interface between air and medium that we had previously developed for the rats (Habert et al. 1991, Lecerf et al. 1993) and humans (Lambrot et al. 2006a,b). This method is briefly described in the legend of Fig. 1. Culture medium, which did not contain biological factors or hormones, was completely changed every $24 \mathrm{~h}$. For each fetus, after $24 \mathrm{~h}$ of culture in control medium (D0), one testis was cultured in the absence (untreated) and the other one in the presence of MEHP at concentrations ranging from $10^{-6}$ to $10^{-4} \mathrm{M}$ for 3 days (D1-D3). The daily testosterone secretion was measured by radioimmunoassay and the values at D1-D3 were normalized to the D0 secretion of the same testicular explant. Values (mean \pm S.E.M.) were then expressed as the percentage of the normalized secretion of the treated explant compared with that of the untreated explant. For human samples, $n=3$ for $10^{-6} \mathrm{M}, n=3$ for $10^{-5} \mathrm{M}$ and $n=15$ for $10^{-4} \mathrm{M}$. For rat samples, $n=5-7$ for the three concentrations. ${ }^{*} P<0.05$, ${ }^{* *} P<0.01,{ }^{* * *} P<0.001$ compared with untreated testis using the Wilcoxon's non-parametric paired test. Values for human testis cultures are from Lambrot et al. (2009).

production is at least 100-fold lower for human than for rat and mouse fetal testes (N'Tumba-Byn et al. 2012). Specifically, $0.01 \mu \mathrm{M}$ BPA (i.e. a concentration relevant to human internal exposure) is sufficient to decrease testosterone production in human fetal testes, whereas concentrations as high as 1 or $10 \mu \mathrm{M}$ are necessary in mouse and rat explants. 
In vivo investigations of BPA effect upon fetal Leydig cell function led to contradictory conclusions. Exposure to high doses of BPA during pregnancy reduced plasma testosterone at birth in the rat (Tanaka et al. 2006). Administration of low doses (50 $\mu \mathrm{g} / \mathrm{kg}$ per day) $\mathrm{BPA}$ to pregnant rats reduced the anogenital distance (AGD) in male pups, whereas lower BPA doses had no effect (Murray et al. 2007). To the contrary, three other independent studies did not show any effect of BPA on AGD after gestational administration of various doses from 1 to $50000 \mu \mathrm{g} / \mathrm{kg}$ per day (Kobayashi et al. 2002, Tyl et al. 2002, Howdeshell et al. 2008). In humans, a recent retrospective epidemiological study highlighted that sons of workers who were professionally exposed to high levels of BPA during pregnancy had shorter AGD (Miao et al. 2011). However, no increase in BPA concentration in umbilical cord blood was observed in newborns with cryptorchidism (Fenichel et al. 2012).

\section{Diethylstilboestrol}

The FeTA system showed that DES clearly impairs both steroidogenesis and gametogenesis in rat and mouse, but not human fetal testis explants (Delbès et al. 2007, N'Tumba-Byn et al. 2012 and Habert R, Lambrot R, Grisin T, Moison D, Livera G \& Rouiller-Fabre V personal data). This is puzzling because it has been reported that in utero exposure to DES is associated with TDS (hypospermia, testicular cancer, hypospadias and cryptorchidism), although the data about the increased risk of testicular cancer following in utero DES exposure remain conflicting (reviewed in Delbès et al. (2006) and Mitchell etal. (2013)). The absence of DES effect on human fetal testicular steroidogenesis was confirmed recently using the xenograft model (Mitchell et al. 2013). This suggests that DES effects in utero on human testes concern endpoints that have not been yet studied, such as a direct effect on the genital tract or INSL3 secretion. Alternatively, it could impair the molecular differentiation of gonocytes in such a way to produce a delayed effect that can be detected only at later stages of development or in adult life. Further studies are needed to address this point.

\section{Depleted uranium}

To our knowledge, no data on the in vivo effect of depleted uranium on the development of the fetal testis are available. The effect of non-radioactive uranium was assessed using the FeTA system only in human and mouse testis explants (Angenard et al. 2011). Uranium, even at high concentrations $(100 \mu \mathrm{M})$, did not affect testosterone production in both species. Conversely, it decreased the number of gonocytes by inducing apoptosis. The NOAEL is between 10 and $50 \mu \mathrm{M}$ for human testis and around $100 \mu \mathrm{M}$ for mouse testis.

\section{Cadmium}

The effects of cadmium were also compared only in the human and mouse species using the FeTA system (Angenard et al. 2010). Steroidogenesis was not affected by cadmium in both species, whereas the number of gonocytes was reduced by increased apoptosis. The NOAEL ranges were between 0.1 and $1 \mu \mathrm{M}$ for human testis and between 1 and $10 \mu \mathrm{M}$ for mouse testis. In vivo, gonadal development in mouse embryos exposed to cadmium in early organogenesis was studied by Tam \& Liu (1985). Genital ridge size was reduced in exposed animals, with retarded germ cell migration into the ridges, resulting in depleted populations of germ cells, defective maturation of gametes and subfertility in male offspring.

\section{Metformin}

Metformin is an anti-diabetic drug that is used to treat gestational diabetes and polycystic ovary syndrome. In the FeTA system, metformin reduces testosterone secretion in both human and mouse testis explants, but the NOAEL is $<50 \mu \mathrm{M}$ for human testis and around $500 \mu \mathrm{M}$ for mouse testis (Tartarin et al. 2012). This result is important because the $50 \mu \mathrm{M}$ level is in the range of concentrations measured in human plasma during therapeutic treatment. In agreement with the in vitro approach, daily administration of $300 \mathrm{mg} / \mathrm{kg}$ per day metformin to pregnant mice from $0.5 \mathrm{dpc}$ induced a decrease in the fetal testicular testosterone content at $16.5 \mathrm{dpc}$ (Tartarin et al. 2012).

\section{Retinoic acid}

In the FeTA system, RA has a positive steroidogenic effect in human fetal testes (but only when younger than $7 \mathrm{GW}$ ) and in mouse fetal testes but a negative effect in rat fetal testes (Livera et al. 2000, Lambrot et al. 2006a, Livera G \& Habert R personal data). Concerning gametogenesis, RA increases mitosis but also apoptosis (more strongly) in gonocytes; thus, the overall result was a decrease in the total number of gonocytes in cultured rat, mouse and human testis explants (Livera et al. 2000, Lambrot et al. 2006a, Trautmann et al. 2008, Guerquin MJ, Grisin T, Habert R \& Livera G personal data). Specifically, RA induces meiosis in $12.5 \mathrm{dpc}$ mouse explants, but not in $14.5 \mathrm{dpc}$ rat explants and 6-12 GW human explants. This difference may not be only a consequence of a shift in developmental stage as the effect is retrieved with 11.5 $\mathrm{dpc}$ mouse testes but not in the $13.5 \mathrm{dpc}$ rat testis. We rather favour the hypothesis that male commitment is governed by several pathways, the importance of which varies from one species to another. In agreement with our in vitro results, a mild vitamin A-deficient diet that results in a threefold decrease in plasma retinol concentration in pregnant rat increases the fetal testicular steroidogenesis at $18.5 \mathrm{dpc}$. This study showed that the endogenous 
retinol physiologically inhibits differentiation and/or function of fetal Leydig cells in the rat species (Livera et al. 2004). Similarly, the knockout of RA receptor $\alpha$ $(R A R \alpha)$ results in an increase in the number of germ cells in mouse fetus (Livera $G$ \& Habert $R$ personal data). Furthermore, RA prevents germ cell mitotic arrest both in vitro and in vivo (Trautmann et al. 2008).

\section{Conclusion}

Over the past 10 years, we have compared the effects of six EDs and of RA in rat, mouse and human fetal testis explants using the $\mathrm{r} / \mathrm{m} / \mathrm{h}$ FeTA assay. The results show that these compounds can be classified into three groups based on the species-specific in vitro responses (Fig. 3). In the first group (with white background in Fig. 3), the in vitro response to a given compound is similar across the three species. In the second group (with grey background in Fig. 3), the response is qualitatively similar, but the NOAEL is different. For instance, the effect of cadmium and uranium on gonocyte development and the effect of BPA and metformin on steroidogenesis are qualitatively similar in three species, but the susceptibility is higher in humans than in rodents. These species differences probably result from differences in the expression of signalling pathways or endogenous hormonal production. Particularly, when considering the negative effect of BPA on steroidogenesis, its NOAEL is more than 100-fold lower in humans than in rodents. This raises concerns because the Sanitary Agencies routinely apply a security factor of 100 when extrapolating rodent data on BPA to human risk assessment. The third group (with black background in Fig. 3) includes compounds that show qualitative differences in the three species: phthalate effect on steroidogenesis, DES effect on gametogenesis and steroidogenesis and RA effect on steroidogenesis. This suggests that there are fundamental differences in the signalling pathways of phthalates, DES and RA in humans and rodents. For instance, the absence of DES effect in human fetal Leydig cells can be explained by the fact that ERS1 is not expressed in human fetal testis (Gaskell et al. 2003). More detailed studies must be performed to evaluate the endocrine differences and the various signalling pathways and molecular targets in human and rodent testes. Another surprising finding of this comparison is that some compounds, such as phthalates and RA, can have a stimulatory effect in mice and an inhibitory effect in rats. This may result from species differences in the rate-limiting steps of the steroid synthesis pathway or in the cellular localization of steroidogenic enzymes. Indeed, aromatase is mainly localized in Sertoli cells in rats and in Leydig cells in mice (Borday et al. 2013).

In conclusion, our findings obtained using the $\mathrm{r} / \mathrm{m} / \mathrm{h}$ FeTA assay show that the threshold of susceptibility to chemicals differs between human and rodent fetal testes for one third the tested compounds. Importantly, the very existence of a response, whatever the dose of the chemical, differs as a function of the species in another third of the cases. Depending on the chemical and on the biological function, its effect may be more intense or less adverse in human than in rodent testes. This raises concerns about the widespread use of rodent models to assess the adverse effects of EDs on human health. This study highlights the need to develop specific tools to study reprotoxicity specifically in humans and the importance of widening our knowledge on the molecular and endocrine differences between human and rodent fetal testis.

\section{Discussion from meeting}

Pia Juul Nielsen (Copenhagen, Denmark): Are you indicating that you can use in vitro experimental studies to predict adverse effects, but you cannot predict the safe levels? You see responses in mice, rats and humans but at different dose levels.

R Habert (Fontenay aux roses, France): In our in vitro system named FeTA, the dose-response curve allows us to clearly define the no observed adverse level (NOAEL) and the lowest observed adverse effect level of one endocrine disruptor (ED) acting directly on the fetal testis. Obviously this is only one experimental approach and the FeTA results must be compared with other approaches to define the safe level in real life, which is a very difficult challenge. Importantly, if in the FeTA system, a given dose level of one compound shows no effect in humans, but effects are seen in rats and mice, or the opposite, it will be important to investigate the mechanisms of action of the compound in relation to species differences in its signalling pathway.

Pia Juul Nielsen: Your in vitro experiments with phthalates showed adverse effects in mice, rats and humans, therefore, it seems that these levels are not safe.

Richard Sharpe (Edinburgh, UK): There are differences depending on the endpoint assessed. Effects are variable for some endpoints (e.g. steroidogenesis), but there is more consistency when looking at the effects on germ cells. It is difficult to extrapolate from in vitro results to the in vivo situation, however.

R Habert: Using FeTA, we were very surprised to find that phthalates and DES did not reduce the production of testosterone by the fetal testis in human, which is opposite to the rat. Richard Sharpe et al. have also observed this recently using the xenograft approach. This is one additional validation of the in vitro approach.

Niels E Skakkebæk (Copenhagen, Denmark): Have you found greater variability in human cultures compared to animal cultures? There is much inconsistency in human populations, for example, we found a marked variation in quality of spermatogenesis in 5000 normal young men. Is there more variation in humans than animals? We would also expect variation in human fetal development.

R Habert: We observe a greater variability in human cultures than rodent ones. Humans being exposed to a 
variable environment whereas rodents have a uniform stable environment can explain this. Also, the method of preparing animal cultures is standardized but it is variable in humans. As an example, the delay between abortion and obtaining the fetal testes is variable. Lastly, there are many polymorphisms in human and not in pure rodent strains.

Niels E Skakkebæk: Although experimental procedures are as constant as possible, there must be inherent differences in the fetuses themselves, and rare cases could have Sertoli-cell-only testes.

Richard Sharpe: There is considerable variation in the level of testosterone production by xenografts of fetal testes from different human fetuses in Rod Mitchell's xenograft studies in nude mice. We do not have an obvious explanation for this between-fetus variation, but it is real. All of these were normal testes with germ cells.

Ulla Hass (Søborg, Denmark): There are species differences when comparing developmental toxicants in humans and animals. Substances should be evaluated as ED compounds (EDCs) if endocrine effects are seen in both rodents and humans, even if the specific effects are different.

R Habert: Species differences do not allow us to exclude phthalates as EDCs. Effects of phthalates largely change as the function of the species when considering the fetal Leydig cell function but they constantly reduce the number of gonocytes by increasing their apoptosis in rat, mouse and human. The rat model is relevant and important to human risk assessment when choosing a common effect in both species (such as gonocytes development when considering the phthalates). The recommended safe dose for humans is generally built by extrapolation from animal data using a safety factor equal to ten to account for species differences. However, the French National Heath Safety in Food, Environment and Work (ANSES) has recently used a factor for species differences equal to 30 to estimate the NOAEL for BPA.

Luiz França (Belo Horizonte, Brazil): In rats, there is a strong interaction between macrophages and Leydig cells. Does this have a role on the endocrine disrupting effects of phthalates?

R Habert: We have not examined the effects of EDCs on macrophages. Macrophages develop in vivo in the rat fetal testis, and 20 years ago we showed that the same development occurred in our in vitro culture system.

\section{Declaration of interest}

The authors declare that there is no conflict of interest that could be perceived as prejudicing the impartiality of the research reported.

\section{Funding}

The work of our group presented in this paper was supported by UniversitéParis Diderot-Paris 7, CEA, INSERM, the French Agence pour la Santé et la Sécurité dans I'Environnement et le
Travail (AFSSET), the French Agence Nationale de Sécurité Sanitaire de I'Alimentation, de l'Environnement et du Travail (ANSES Contrat EST62010/2/046), the Agence Nationale de la Recherche (ANR, contrat Phtalatestis and contrat MECABPA) and the Ministère de l'Ecologie, du Développement Durable, des Transports et du Logement (Programme ANTIOPES Storm). None of the authors received any personal financial remuneration or funding for research studies from any chemical industrial company.

\section{Author contribution statement}

V Muczynski, T Grisin, D Moison and S Messiaen performed the experiments for the original data presented here. V Muczynski, T Grisin, D Moison, S Messiaen, R Lambrot, A Lehraiki, T N'Tumba-Byn, M-J Guerquin, C Levacher and $G$ Livera performed the experiments for personal data. $\mathrm{V}$ Rouiller-Fabre, A Benachi and R Frydman supervised the collection of human fetal testes. $\mathrm{R}$ Habert headed the group. G Delbes, V Rouiller-Fabre and G Livera contributed to critically reviewing the draft manuscript that was written by $\mathrm{R}$ Habert.

\section{Acknowledgements}

The authors are grateful to Aurélie Gouret for secretarial assistance and to E Andermarcher for editing the English manuscript. They also thank Véronique Neuville for animal care and the staff of the Department of Obstetrics and Gynaecology of the Antoine Béclère Hospital (Clamart, France). This review is dedicated to René Habert's mentor, Jose M Saez.

\section{References}

Angenard G, Muczynski V, Coffigny H, Pairault C, Duquenne C, Frydman R, Habert R, Rouiller-Fabre V \& Livera G 2010 Cadmium increases human fetal germ cell apoptosis. Environmental Health Perspectives 118 331-337. (doi:10.1289/ehp.0900975)

Angenard G, Muczynski V, Coffigny H, Duquenne C, Frydman R, Habert R, Livera G \& Rouiller-Fabre V 2011 In vitro effects of uranium on human fetal germ cells. Reproductive Toxicology 31 470-476. (doi:10.1016/ j.reprotox.2010.12.058)

Barlow NJ, Phillips SL, Wallace DG, Sar M, Gaido KW \& Foster PM 2003 Quantitative changes in gene expression in fetal rat testes following exposure to di(n-butyl) phthalate. Toxicological Sciences 73 431-441. (doi:10.1093/toxsci/kfg087)

Bay K, Main KM, Toppari J \& Skakkebaek NE 2011 Testicular descent: INSL3, testosterone, genes and the intrauterine milieu. Nature Reviews. Urology 8 187-196. (doi:10.1038/nrurol.2011.23)

Bendsen E, Laursen S, Olesen C, Westergaard L, Andersen C \& Byskov A 2001 Effect of 4-octylphenol on germ cell number in cultured human fetal gonads. Human Reproduction 16 236-243. (doi:10.1093/humrep/16.2.236)

Borday C, Merlet J, Racine C \& Habert R 2013 Expression and localization of aromatase during fetal mouse testis development. Basic and Clinical Andrology 23 12-17. (doi:10.1186/2051-4190-23-12)

Boulogne B, Olaso R, Levacher C, Durand P \& Habert R 1999 Apoptosis and mitosis in gonocytes of the rat testis during foetal and neonatal development. International Journal of Andrology 22 356-365. (doi:10.1046/ j.1365-2605.1999.00191.x)

Boulogne B, Habert R \& Levacher C 2003 Regulation of the proliferation of cocultured gonocytes and Sertoli cells by retinoids, triiodothyronine, and 
intracellular signaling factors: differences between fetal and neonatal cells. Molecular Reproduction and Development 65 194-203. (doi:10.1002/ mrd.10311)

Chauvigné F, Menuet A, Lesne L, Chagnon MC, Chevrier C, Regnier JF, Angerer J \& Jégou B 2009 Time- and dose-related effects of di-(2-ethylhexyl) phthalate and its main metabolites on the function of the rat fetal testis in vitro. Environmental Health Perspectives 117 515-521. (doi:10.1289/ ehp.11870)

Cupp AS \& Skinner MK 2001 Actions of the endocrine disruptor methoxychlor and its estrogenic metabolite on in vitro embryonic rat seminiferous cord formation and perinatal testis growth. Reproductive Toxicology 15 317-326. (doi:10.1016/S0890-6238(01)00124-1)

Delbès G, Levacher C, Duquenne C, Racine C, Pakarinen P \& Habert R 2005 Endogenous estrogens inhibit mouse fetal Leydig cell development via estrogen receptor $\alpha$. Endocrinology 146 2454-2461. (doi:10.1210/ en.2004-1540)

Delbès G, Levacher C \& Habert R 2006 Estrogen effects on fetal and neonatal testicular development. Reproduction 132 527-538. (doi:10. 1530/rep.1.01231)

Delbès G, Duquenne C, Szenker J, Taccoen J, Habert R \& Levacher C 2007 Developmental changes in testicular sensitivity to estrogens throughout fetal and neonatal life. Toxicological Sciences 99 234-243. (doi:10. 1093/toxsci/kfm160)

Fenichel P, Dechaux H, Harthe C, Gal J, Ferrari P, Pacini P, WagnerMahler K, Pugeat M \& Brucker-Davis F 2012 Unconjugated bisphenol A cord blood levels in boys with descended or undescended testes. Human Reproduction 27 983-990. (doi:10.1093/humrep/der451)

Ferrara D, Hallmark N, Scott HM, Brown R, McKinnell C, Mahood IK \& Sharpe RM 2006 Acute and long-term effects of in utero exposure of rats to di(n-butyl) phthalate on testicular germ cell development and proliferation. Endocrinology 147 5352-5362. (doi:10.1210/en.2006-0527)

Franke FE, Pauls K, Rey R, Marks A, Bergmann M \& Steger K 2004 Differentiation markers of Sertoli cells and germ cells in fetal and early postnatal human testis. Anatomica Embryologica 209 169-177. (doi:10.1007/s00429-004-0434-x)

Gaskell TL, Robinson LL, Groome NP, Anderson RA \& Saunders PT 2003 Differential expression of two estrogen receptor $\beta$ isoforms in the human fetal testis during the second trimester of pregnancy. Journal of Clinical Endocrinology and Metabolism 88 424-432. (doi:10.1210/jc.2002-020811)

Gaskell TL, Esnal A, Robinson LL, Anderson RA \& Saunders PT 2004 Immunohistochemical profiling of germ cells within the human fetal testis: identification of three subpopulations. Biol Reprod 71 2012-2021.

Habert R \& Brignaschi P 1991 Developmental changes in in vitro testosterone production by dispersed Leydig cells during late fetal life in the rat. Archives of Andrology 27 65-71. (doi:10.3109/0148501 9108987654)

Habert R \& Picon R 1982 Control of testicular steroidogenesis in foetal rat: effect of decapitation on testosterone and plasma luteinizing hormonelike activity. Acta Endocrinologica 99 466-473. (doi:10.1530/acta.0. 0990466)

Habert R \& Picon R 1984 Testosterone, dihydrotestosterone and estradiol$17 \beta$ levels in maternal and fetal plasma and in fetal testes in the rat. Journal of Steroid Biochemistry 21 193-198. (doi:10.1016/0022-4731 (84)90383-2)

Habert R, Devif I, Gangnerau MN \& Lecerf L 1991 Ontogenesis of the in vitro response of rat testis to gonadotropin-releasing hormone. Molecular and Cellular Endocrinology 82 199-206. (doi:10.1016/ 0303-7207(91)90032-N)

Habert R, Lejeune H \& Saez JM 2001 Origin, differentiation and regulation of fetal and adult Leydig cells. Molecular and Cellular Endocrinology 179 47-74. (doi:10.1016/S0303-7207(01)00461-0)

Habert R, Muczynski V, Lehraiki A, Lambrot R, Lecureuil C, Levacher C, Coffigny H, Pairault C, Moison D, Frydman R et al. 2009 Adverse effects of endocrine disruptors on the fetal testis development: focus on the phthalates. Folia Histochemica et Cytobiologica 47 S67-S74. (doi:10.2478/v10042)

Hallmark N, Walker M, McKinnell C, Mahood IK, Scott H, Bayne R, Coutts S, Anderson RA, Greig I, Morris K et al. 2007 Effects of monobutyl and di(n-butyl) phthalate in vitro on steroidogenesis and Leydig cell aggregation in fetal testis explants from the rat: comparison with effects in vivo in the fetal rat and neonatal marmoset and in vitro in the human. Environmental Health Perspectives 115 390-396. (doi:10.1289/ehp.9490)
Heger NE, Hall SJ, Sandrof MA, McDonnell EV, Hensley JB, McDowell EN, Martin KA, Gaido KW, Johnson KJ \& Boekelheide K 2012 Human fetal testis xenografts are resistant to phthalate-induced endocrine disruption. Environmental Health Perspectives 120 1137-1143. (doi:10.1289/ ehp.1104711)

Howdeshell KL, Furr J, Lambright CR, Wilson VS, Ryan BC \& Gray LE Jr 2008 Gestational and lactational exposure to ethinyl estradiol, but not bisphenol A, decreases androgen-dependent reproductive organ weights and epididymal sperm abundance in the male long evans hooded rat. Toxicological Sciences 102 371-382. (doi:10.1093/toxsci/kfm306)

Kobayashi K, Miyagawa M, Wang RS, Sekiguchi S, Suda M, Sekiguchi S \& Honma T 2002 Effects of in utero and lactational exposure to bisphenol A on somatic growth and anogenital distance in F1 rat offspring. Industrial Health 40 375-381. (doi:10.2486/indhealth.40.375)

Lambrot R, Coffigny H, Pairault C, Frydman R, Habert R \& Rouiller-Fabre V 2006a Use of organ culture to study the human fetal testis development: effect of retinoic acid. Journal of Clinical Endocrinology and Metabolism 91 2696-2703. (doi:10.1210/jc.2005-2113)

Lambrot R, Livera G, Coffigny H, Pairault C, Frydman R, Habert R \& RouillerFabre V 2006b A new method for toxicity assays on human and mouse fetal testis. Biochimie 88 1831-1835. (doi:10.1016/j.biochi.2006. 09.022)

Lambrot R, Muczynski V, Lécureuil C, Angenard G, Coffigny H, Pairault C, Moison D, Frydman R, Habert R \& Rouiller-Fabre V 2009 Phthalates impair germ cell development in the human fetal testis in vitro without change in testosterone production. Environmental Health Perspectives 117 32-37. (doi:10.1289/ehp.1174c32)

Lecerf L, Rouiller-Fabre V, Levacher C, Gautier C, Saez J \& Habert R 1993 Stimulatory effect of follicle-stimulating hormone on basal and luteinizing hormone-stimulated testosterone secretion by fetal rat testis in vitro. Endocrinology 133 2313-2318. (doi:10.1210/endo.133.5.8404683)

Lehraiki A, Racine C, Krust A, Habert R \& Levacher C 2009 Phthalates impair germ cell number in the mouse fetal testis by an androgen- and estrogen-independent mechanism. Toxicological Sciences 111 372-382. (doi:10.1093/toxsci/kfp153)

Leridon H \& Slama R 2008 The impact of a decline in fecundity and of pregnancy postponement on final number of children and demand for assisted reproduction technology. Human Reproduction 23 1312-1319. (doi:10.1093/humrep/den106)

Li H \& Kim KH 2003 Effects of mono-(2-ethylhexyl) phthalate on fetal and neonatal rat testis organ cultures. Biology of Reproduction 69 1964-1972. (doi:10.1095/biolreprod.103.018895)

Livera G, Rouiller-Fabre V, Durand P \& Habert R 2000 Multiple effects of retinoids on the development of Sertoli, germ and Leydig cells of fetal and neonatal rat testis in culture. Biological Reproduction 62 1303-1314. (doi:10.1095/biolreprod62.5.1303)

Livera G, Pairault C, Lambrot R, Lelievre-Pegorier M, Saez JM, Habert R \& Rouiller-Fabre V 2004 Retinoid-sensitive steps in steroidogenesis in fetal and neonatal rat testes: in vitro and in vivo studies. Biological Reproduction 70 1814-1821. (doi:10.1095/biolreprod.103.021451)

Livera G, Delbès G, Pairault C, Rouiller-Fabre V \& Habert R 2006 Organotypic culture, a powerful model for studying rat and mouse fetal testis development. Cell and Tissue Research 324 507-521. (doi:10.1007/s00441-006-0167-7)

Main KM, Skakkebaek NE, Virtanen HE \& Toppari J 2010 Genital anomalies in boys and the environment. Best Practice \& Research. Clinical Endocrinology \& Metabolism 24 279-289. (doi:10.1016/j.beem.2009.10.003)

Miao M, Yuan W, He Y, Zhou Z, Wang J, Gao E, Li G \& Li DK 2011 In utero exposure to bisphenol-A and anogenital distance of male offspring. Birth Defects Research. Part A, Clinical and Molecular Teratology 91 867-872. (doi:10.1002/bdra.22845)

Migrenne S, Pairault C, Racine C, Livera G, Géloso A \& Habert R 2001 Luteinizing hormone-dependent activity and luteinizing hormoneindependent differentiation of rat fetal Leydig cells. Molecular and Cellular Endocrinology 172 193-202. (doi:10.1016/S0303-7207(00)00339-7)

Mitchell RT, Saunders PT, Childs AJ, Cassidy-Kojima C, Anderson RA, Wallace WH, Kelnar CJ \& Sharpe RM 2010 Xenografting of human fetal testis tissue: a new approach to study fetal testis development and germ cell differentiation. Human Reproduction 25 2405-2414. (doi:10.1093/ humrep/deq183)

Mitchell RT, Childs AJ, Anderson RA, van den Driesche S, Saunders PT, McKinnell C, Wallace WH, Kelnar CJ \& Sharpe RM 2012 Do phthalates 
affect steroidogenesis by the human fetal testis? Exposure of human fetal testis xenografts to di-n-butyl phthalate. Journal of Clinical Endocrinology and Metabolism 97 E341-E348. (doi:10.1210/jc.2011-2411)

Mitchell RT, Sharpe RM, Anderson RA, McKinnell C, Macpherson S, Smith LB, Wallace WH, Kelnar CJ \& van den Driesche S 2013 Diethylstilboestrol exposure does not reduce testosterone production in human fetal testis xenografts. PLoS ONE 8 e61726. (doi:10.1371/journal.pone.0061726)

Muczynski V, Cravedi JP, Lehraiki A, Levacher C, Moison D, Lecureuil C, Messiaen S, Perdu E, Frydman R, Habert R et al. 2012 Effect of mono(2-ethylhexyl) phthalate on human and mouse fetal testis: in vitro and in vivo approaches. Toxicology and Applied Pharmacology 261 97-104. (doi:10.1016/j.taap.2012.03.016)

Murray TJ, Maffini MV, Ucci AA, Sonnenschein C \& Soto AM 2007 Induction of mammary gland ductal hyperplasias and carcinoma in situ following fetal bisphenol A exposure. Reproductive Toxicology 23 383-390. (doi:10.1016/j.reprotox.2006.10.002)

N'Tumba-Byn T, Moison D, Lacroix $M$, Lecureuil $C$, Lesage L, Prud'homme SM, Pozzi-Gaudin S, Frydman R, Benachi A, Livera G et al. 2012 Differential effects of bisphenol A and diethylstilbestrol on human, rat and mouse fetal Leydig cell function. PLoS ONE 7 e51579. (doi:10.1371/journal.pone.0051579)

Olaso R \& Habert R 2000 Genetic and cellular analysis of male germ cell development. Journal of Andrology 21 497-511. (doi:10.1002/j.19394640.2000.tb02114.x)

Olaso R, Pairault C, Boulogne B, Durand P \& Habert R 1998 Transforming growth factor $\beta 1$ and $\beta 2$ reduce the number of gonocytes by increasing apoptosis. Endocrinology 139 733-740. (doi:10.1210/endo.139.2.5765)

Olesen IA, Sonne SB, Hoei-Hansen CE, Rajpert-De Meyts E \& Skakkebaek NE 2007 Environment, testicular dysgenesis and carcinoma in situ testis. Best Practice \& Research. Clinical Endocrinology \& Metabolism 21 462-478. (doi:10.1016/j.beem.2007.04.002)

O'Shaughnessy PJ \& Fowler PA 2011 Endocrinology of the mammalian fetal testis. Reproduction 141 37-46. (doi:10.1530/REP-10-0365)

Pauls K, Schorle H, Jeske W, Brehm R, Steger K, Wernert N, Buttner R \& Zhou H 2006 Spatial expression of germ cell markers during maturation of human fetal male gonads: an immunohistochemical study. Human Reproduction 21 397-404. (doi:10.1093/humrep/dei325)

Petre-Lazar B, Livera G, Moreno SG, Trautmann E, Duquenne C, Hanoux V, Habert R \& Coffigny H 2007 The role of p63 in germ cell apoptosis in the developing testis. Journal of Cellular Physiology 210 87-98. (doi:10.1002/jcp.20829)

Robinson LL, Townsend J \& Anderson RA 2003 The human fetal testis is a site of expression of neurotrophins and their receptors: regulation of the germ cell and peritubular cell population. Journal of Clinical Endocrinology and Metabolism 88 3943-3951. (doi:10.1210/jc.2003-030196)

Rouiller-Fabre V, Lecerf L, Gautier C, Saez JM \& Habert R 1998 Expression and effect of insulin-like growth factor I on rat fetal Leydig cell function and differentiation. Endocrinology 139 2926-2934. (doi:10.1210/endo. 139.6.6035)

Rouiller-Fabre V, Muczynski V, Lambrot R, Lécureuil C, Coffigny $\mathbf{H}$, Pairault C, Moison D, Angenard G, Bakalska M, Courtot AM et al. 2009 Ontogenesis of testicular function in humans. Folia Histochemica et Cytobiologica 47 S19-S24. (doi:10.2478/v10042-009-0065-4)

Scott HM, Mason JI \& Sharpe RM 2009 Steroidogenesis in the fetal testis and its susceptibility to disruption by exogenous compounds. Endocr Rev 30 883-925.
Sharpe RM 2012 Sperm counts and fertility in men: a rocky road ahead. Science \& Society Series on Sex and Science. EMBO Reports 13 398-403. (doi:10.1038/embor.2012.50)

Sharpe RM \& Irvine DS 2004 How strong is the evidence of a link between environmental chemicals and adverse effects on human reproductive health? BMJ 328 447-451. (doi:10.1136/bmj.328.7437.447)

Sharpe RM \& Skakkebaek NE 1993 Are oestrogens involved in falling sperm counts and disorders of the male reproductive tract? Lancet 341 1392-1395. (doi:10.1016/0140-6736(93)90953-E)

Skakkebaek NE, Rajpert-De Meyts E \& Main KM 2001 Testicular dysgenesis syndrome: an increasingly common developmental disorder with environmental aspects. Human Reproduction 16 972-978. (doi:10.1093/humrep/ 16.5.972)

Stroheker T, Regnier JF, Lassurguere J \& Chagnon MC 2006 Effect of in utero exposure to di-(2-ethylhexyl)phthalate: distribution in the rat fetus and testosterone production by rat fetal testis in culture. Food and Chemical Toxicology 44 2064-2069. (doi:10.1016/j.fct.2006.07.007)

Tam PP \& Liu WK 1985 Gonadal development and fertility of mice treated prenatally with cadmium during the early organogenesis stages. Teratology 32 453-462. (doi:10.1002/tera.1420320314)

Tanaka M, Nakaya S, Katayama M, Leffers H, Nozawa S, Nakazawa R, Iwamoto T \& Kobayashi S 2006 Effect of prenatal exposure to bisphenol A on the serum testosterone concentration of rats at birth. Human \& Experimental Toxicology 25 369-373. (doi:10.1191/ 0960327106ht638oa)

Tartarin P, Moison D, Guibert E, Dupont J, Habert R, Rouiller-Fabre V, Frydman N, Pozzi S, Frydman R, Lecureuil C et al. 2012 Metformin exposure affects human and mouse fetal testicular cells. Human Reproduction 27 3304-3314. (doi:10.1093/humrep/des264)

Trautmann E, Guerquin MJ, Duquenne C, Lahaye JB, Habert R \& Livera G 2008 Retinoic acid prevents germ cell mitotic arrest in mouse fetal testes. Cell Cycle 7 656-664. (doi:10.4161/cc.7.5.5482)

Tyl RW, Myers CB, Marr MC, Thomas BF, Keimowitz AR, Brine DR, Veselica MM, Fail PA, Chang TY, Seely JC et al. 2002 Three-generation reproductive toxicity study of dietary bisphenol A in CD SpragueDawley rats. Toxicological Sciences 68 121-146. (doi:10.1093/ toxsci/68.1.121)

Vandenberg LN, Colborn T, Hayes TB, Heindel JJ, Jacobs DR Jr, Lee DH, Shioda T, Soto AM, vom Saal FS, Welshons WV et al. 2012 Hormones and endocrine-disrupting chemicals: low-dose effects and nonmonotonic dose responses. Endocrine Reviews 33 378-455. (doi:10.1210/ er.2011-1050)

Vergouwen RP, Jacobs SG, Huiskamp R, Davids JA \& de Rooij DG 1991 Proliferative activity of gonocytes, Sertoli cells and interstitial cells during testicular development in mice. Journal of Reproduction and Fertility 93 233-243. (doi:10.1530/jrf.0.0930233)

Received 2 October 2013

First decision 24 October 2013

Revised manuscript received 21 January 2014

Accepted 4 February 2014 